\title{
Modeling the Effects of Macro-Measures on Elder Health in China: A "Fresh Sample" Approach
}

\author{
Linda Eberst Dorsten (Corresponding Author) \\ Department of Sociology, SUNY-Fredonia \\ Fredonia, NY 14063, USA \\ Tel: 716-673-3469 E-mail: dorsten@fredonia.edu \\ Yuhui Li \\ Department of Sociology, Rowan University \\ Glassboro, NJ, USA \\ Tel: 856-256-4500Ｅ-mail: li@rowan.edu
}

\begin{abstract}
One part of the analysis presented in this paper examines how elder health is affected by macro-measures of regional inequality and socio-environmental conditions. Unique data from Chinese Longitudinal Healthy Longevity Survey (CLHLS) provide demographic, socio-economic and health information about China elders, including oldest-old (ages 80-105). To examine the effects of macro-level variables on elder self-rated health, we use data from the 1998 wave (baseline), and add macro-level indicators of environmental conditions, SES, and demographic characteristics not in the CLHLS. However, censoring due to deaths and dropouts is very high in longitudinal datasets of the elderly including the CLHLS, and samples can vary by data wave. Therefore, a second part of our analysis includes only new respondents added in the 2000 wave -- a "fresh sample" for a validation test of our model.
\end{abstract}

Keywords: Elder health, Self-rated health, China, Macro-Measures, Regional inequality, Socio-environmental conditions, Sample attrition, Replacement sample

\section{Elder Health: Conceptual and Methodological Issues}

The literature on the health of individuals has focused on two theories describing the pathways leading to health inequalities: a "social stress" or psychological approach, which examines how social capital resources mitigate stress, and a "materialistic" approach, in which material conditions at different social-economic levels affect health (Mansyur et al. 2008 offers an overview of these literatures). Findings from studies employing a "materialistic" approach generally agree that individual socio-economic status (SES) is a persistent predictor of health. Studies taking a "social stress" or psychological approach also report that individual SES is a persistent predictor of health.

However, findings from both social stress and materialistic perspectives increasingly suggest that micro-level measures such as SES do not capture all influences affecting health, particularly in less wealthy countries. For example, scholars argue that macro-level measures must be taken into consideration in order to fully comprehend the mechanisms through which health inequality operates (Robert 1998; Robert and House 2000; Wilkinson 2002). There is growing consensus that the effect of income inequality on health can reflect various structural conditions, such as discrimination, dominance hierarchies, and underinvestment in human or social infrastructure, which can be influenced by cultural norms and values (Zimmer et al. 2000; Mansyur et al. 2008). For example, Zimmer et al. (2000) examine self-assessed elder health in the Philippines, Taiwan and Thailand. Even under controls for all covariates in their model and interaction effects, Zimmer et al. find some substantial country differences for self-assessed health. Their explanations include absence of macro-level measures (e.g., cultural influences which could affect health assessment, such as modesty in health reporting) and uneven access to health care by country (e.g., conditions such as heart disease not diagnosed professionally when payment is out-of-pocket). Zimmer and Kwong (2004) point out that the association between SES and health rarely has been studied where levels of economic development and stratification systems differ from those in Western developed countries, although they expect that the SES-health association is quite robust. 
To date, research shows little consensus about the health effects from macro-level measures such as regional or community SES, and regional or neighborhood inequality. For example, Zeng (2004) finds that the oldest-old ( 85 years and older) in rural China have a higher life expectancy than their urban counterparts. On the other hand, Zimmer and Kwong (2004) find no significant difference between urban and rural elders in self-assessed health when education is used to explain health, although high income elders report higher level of chronic disorders than those with lower SES (see also Sen 1998). Various other indicators of SES have been examined in prior studies, such as bank savings and pension status, with inconsistent and unclear results. It also is unclear whether cultural indicators should be measured at the neighborhood, county, state, regional or country level (Subramanian et al. 2002).

Yet a pattern is emerging that macro-level SES, like micro-level SES, is positively related to population health. For example, residents in poverty-stricken communities have poorer health compared with residents in wealthy communities in both Western and non-Western countries, especially when health comparisons are measured by mortality and morbidity (Liu et al. 2001; Robert 1998; Wilson 1987). Differences in regional or community SES also can determine availability and accessibility of health care services. Perhaps most essential in addressing possible model misspecification is research that combines micro- and macro-levels of units of analysis, because individual health status is likely a result of both (Robert 1998; Robert and House 2000). In short, one concern in modeling elder health is that models have generated findings that are inconsistent, possibly due to model misspecification or measurement error (Zeng 2004).

A second concern in modeling elder health and other aspects of elder life using longitudinal data is censoring due to deaths and dropouts. Longitudinal data from less developed counties are particularly at risk of attrition, with the special issues surrounding measurement of elder health compounding the potential for inaccurate information. For example, in the introduction to their assessment of reliability of mortality and morbidity of elders in the Chinese Longitudinal Healthy Longevity Survey dataset, Gu and Dupre (2008) caution that when studying mortality

(u)nlike respondent deaths in most longitudinal surveys in Western nations, which can be linked to a national death database with relatively accurate mortality reports, the survival status of respondents in longitudinal surveys in most developing countries are often collected through interviews. Consequently, mortality data from studies in developing countries may introduce inaccuracies due to age exaggeration and age-at-death misreporting by proxies, which are further confounded by sample attrition and selection. Such inaccuracies may well introduce biases in the estimation of associations between the study variables and mortality, and lead researchers to draw incorrect conclusions (p. 3).

As $\mathrm{Gu}(2008$, p. 11) points out, if sample attrition is related to attributes of the sample, biased estimates of coefficients might occur. A variety of articles describe statistical methods currently used to handle censored or missing data (see Hogan et al. 2004; Horton and Fitzmaurice 2002; Priesser et al. 2000). However, some longitudinal datasets themselves can be utilized for evaluating the potential effects of sample attrition on model misspecification.

In the present study, we employ two waves of data to propose and test a model of the effects of macro-level measures on the health status of elder populations, who are known to have relatively high levels of attrition. A second part of our analysis includes only new respondents added in the 2000 wave -- a "fresh sample" for a validation test of our model. By testing our model using cross-sectional data, we avoid sample attrition across data waves.

\subsection{China's Elder Population under Rapid Social Change}

Elder populations around the world are increasing in numbers and proportions, especially the oldest old, and are rising rapidly in most of the more developed and many developing countries. China has one of the most rapidly-growing aging populations in the world, with the largest number of elderly persons and the largest percentage ages 80 and older (Kinsella and Velkoff 2001, p. 20). China's State Family Planning and Population Commission predicts the current $14 \%$ of population ages 65 and older will surge to $24 \%$ by 2050 (Zhang 1999; see also Kaneda 2006). The elder population in China is growing at one of the fastest rates ever recorded (Kaneda 2006; Lee 2004).

China is a developing country measured by conventional standards, but also it is a country that has been experiencing tremendous social, economic, demographic and epidemiological changes in recent decades. In traditional Chinese society, elders live with one of their children, usually a son. In many communities, however, family-based elder care is now impractical because most middle-aged children have little time to care for parents. The health and well-being of Chinese elderly are of increasing concern to world health organizations, 
demographers, environmental experts, public health officials and others worldwide. In short, China is a rapidly changing, aging society in an underdeveloped economy (Lee 2004, p. 330).

Guided by Deng Xiaoping's differential economic development, the Chinese government three decades ago selected the coastal region to spearhead economic reform (Holbig 2004; Shih 2004). The coastal region has benefited from many advantages, including top-down economic and foreign trade policies and abundant human capital and technological resources, while non-coastal regions have not. Important structural changes include village-run industrial development in rural areas, and the reform of state-owned enterprises in urban areas (Li and Dorsten, this issue). Escalating differences in economic development between coastal and non-coastal regions during last two decades have generated tremendous social, political and economic problems predicted to continue.

Institutionalized structural practices and policies in China include differential treatment of people according to ascribed statuses, and according to achieved statuses of party membership, residential location and geographic region (Walder 2003). People in poor communities and areas in China and elsewhere also do not have as much access to health care, particularly quality health care, as do people in wealthier communities and regions (Liu et al. 2003).

However, elder health, especially in rural areas, has received the least systematic research attention, and studies of elders in non-coastal rural provinces of inland and western China still are scant. Social factors such as relative deprivation and unequal distribution of resources of all kinds also have a negative impact on overall health of a population, particularly for children and elders. Some argue that a sense of relative deprivation associated with what Durkheim labels "anomie" -- inadequate social integration and cohesion in communities -- has detrimental impact on both physical and mental health, particularly in lower socio-economic areas (Berkman et al. 2000; Daly et al. 1998; Wilkinson 2002).

Consistent with theory and research that unequal distribution of macro-level resources has a negative impact on population health, we hypothesize that inequality of regional resources believed to be associated with health quality of air and water, availability of sanitary facilities, rate of illiteracy, and old age dependency ratio -- has a detrimental impact on the health status of elders.

\section{Data and Methods}

We employ data from the Chinese Longitudinal Healthy Longevity Survey (CLHLS). The CLHLS conducts face-to-face interviews to collect data on family structure and family support; living arrangements; physical performance and activities of daily living (ADL); chronic disease; economic resources; self-rated health; and various social, economic and psychological characteristics and care needs of respondents. (Note 1) The CLHLS is unique because it has collected extensive information on a much larger population of oldest-old than previously studied (Zeng 2002). (Note 2) To date, five waves of data have been collected from elders ages 65 and older (1998, 2000, 2002, 2005 and 2008). At each wave, survivors were re-interviewed and deceased interviewees were replaced by additional participants. To examine effects of macro-level variables on elder health, we use data from the 1998 wave (baseline) of the CLHLS, and add macro-level indicators of environmental conditions and demographic characteristics measured at the province level (China Statistical Yearbook on Environment, 2006; China Population Statistics Yearbook, 2006). (Note 3)

Of the 31 provinces in China, CLHLS sampling excludes nine rural provinces, mostly in the northwest, where ethnic (non-Han) minorities are a very high proportion of the population. Decisions for exclusion were based on published findings showing age-reporting inaccuracy among oldest-old, particularly in Xinjiang province (Coale and Li 1991; Zeng and Gu 2008). Therefore, our estimates of coefficients properly apply only to elders of the 22 sampled provinces ages 80 years and older (see Notes 1 and 2).

\subsection{Dependent Variable}

Our dependent variable is self-rated health. Studies find that self-rated health is a more valid and reliable measure of health status than are physical indicators (Ross and Bird 1994) and is related to objective health status measures (Ferraro 1980; see also Mossey and Shapiro 1982; Zimmer et al. 2000). Self-related health has been shown to be a superior predictor of mortality even over physician assessments (Ferraro and Farmer 1999). It also is a consistent predictor of mortality cross-nationally (Idler and Benyamini, 1997; also see Mansyur et al. 2008 for a study of self-health ratings in 45 countries). Self-rated health in the CLHLS is obtained by answers to the question, "How do you rate your health at present?" with categories of very good, good, so-so, bad, very bad and unable to answer. Although many CLHLS questions could be answered by a proxy, respondents had to provide their own health assessment. Those unable to answer are excluded from our analysis. Possibly 
non-respondents are in fairly poor health or have cognition problems. Because the variable for self-reported health is skewed toward better health, we created a binary variable by combining responses of 'very good' and 'good' to represent 'good health'. Slightly over one-half of each sample, 59\% in 1998 and $60 \%$ in 2000, report 'good health.'

\subsection{Independent Variables}

Environmental quality increasingly is associated with health status of communities and individuals. Much of the research on pollution in China, however, has focused on cities (e.g., Wong et al. 2008; Shao et al. 2006; Zhang et al. 2006; Chan 1995), where residents in highest socially deprived areas can be at greatest mortality risk from air pollution (Wong et al. 2008). Yet the most critical resource in China is water, with increasing untreated municipal and industrial waste discharges (Wang et al. 2006). Wang et al. found that most untreated discharges are from rural industries due to ineffective implementation of environmental protection laws. In rural areas, drinking water for approximately 190 million rural populations contains substances that exceed health standards (China Ministry of Water Resources, 2010). The 2007 Report on the State of the Environment in China (2008), the most recent report on the Ministry of Environmental Protection's website, illustrates the increasingly critical nature of water quality in China, particularly for rural populations.

The situation of environmental protection in rural areas remained grim. Point pollution and non-point pollution coexisted, domestic pollution was coupled with industrial pollution and newly emerged pollution and old pollution were interwoven. Industrial and urban pollution have gradually shifted to rural areas, threatening the safety of drinking water and farm produce. The rural area faced the dual menaces of environmental pollution and ecological damage. This was represented by exacerbated domestic pollution and non-point pollution, emerging pollution from industrial and mining sources, hidden danger of drinking water and ineffective control of ecological degradation.

The aggregate population benefiting from access to water sanitation improvement accounted for 92.05\%. $62.71 \%$ of the population had access to water supply and $56.97 \%$ had access to sanitary toilet facilities. Environment-friendly toilet facilities covered $34.81 \%$ of the rural population.

For the present study, we chose four province-level measures of environmental quality, three that are indicators of water quality and sanitation (proportion of industrial waste water meeting discharge standards, access rate to sanitary toilets in rural areas, percentage of rural population with access to water sanitation improvement) and one to represent air quality (percentage of gross domestic product [GDP] investment in anti-pollution projects). We also include three province-level socio-demographic measures associated with longevity and well-being: old-age dependency ratio, life expectancy and percentage of illiterate adult population (age 15+ years). We looked at mean differences by province on key macro-level variables and found substantial variation, which supports the use of our macro-variables. We examine our province-level measures as separate variables because they seem to address different aspects of macro-SES. (Note 4)

\subsection{Control Variables}

Our control variables are a variety of individual-level measures about respondents, including several measures of SES (education, occupation and retirement income), one for geographic location of respondent's residence (rural/urban location), and a variety of demographic and personal health status measures (He et al. 2007). Because some questions could be answered by a family member if respondent was unable or did not know the answer, we include controls for proxy responses for all variables in our model that have proxies. (Note 5)

\section{Findings}

As discussed in section 1, censoring is very high in longitudinal datasets including the CLHLS, and samples can vary by data wave. By checking our findings from the 1998 data with a new sample taken two years later by the same agency and from the same population, we provide a cross-validation of our model.

Table 1 presents all variables in the full model, their operational definitions, and descriptive statistics for CLHLS data wave 1 and the "fresh sample" of wave 2.

\section{Table 1 about here}

Table 1 shows that the 1998 respondents and the replacements in wave 2 overall are very similar. However, the 2000 replacement sample is a little older, somewhat more likely to be rural residents and more physically active, and to have more household members than respondents of wave 1 . The replacement sample also is somewhat less likely to have sanitary toilets, access to water-sanitation improvements, and retirement income, not surprising because of their somewhat older average age and rural residence. Proxy responses also are slightly more common in the replacement sample. (Note 6) 
Table 2 presents logistic regression coefficients for self-rated health estimated from wave 1 data $(n=6,835)$. Looking at our macro-variables, a higher percentage of a province's GDP spent on anti-pollution projects increases the likelihood of good health, as does the higher percentage of residents having access to sanitary toilets in rural areas. A higher old-age dependency ratio has a negative effect on good health, as might be expected under competition for scarce resources. A higher percentage of a population with water sanitation improvement in their province is negatively associated with good health, a finding that will be discussed in section 4 . These results emerge under controls for a variety of social, demographic, economic, and health status measures, as Table 2 shows. The model in Table 2 is statistically significant $\left(X^{2}=659.35, \mathrm{df}=24, \mathrm{p}<.000\right)$.

\section{Table 2 about here}

Table 3 shows the logit coefficients for self-rated health estimated from our "fresh sample" respondents $(n=3,763)$, which were added to the CHLHS dataset in wave 2 to replace those lost to follow-up (see Note 6)

All four of our macro-measures with significant coefficients in the 1998 sample also are significant predictors of elder health in the replacement sample of wave 2, with the same direction of effects for each measure for both time periods. Also, self-rated health is higher in provinces with a higher percentage of industrial waste water that meets discharge standards. The model in Table 3 is statistically significant $\left(X^{2}=670.77, \mathrm{df}=24, \mathrm{p}<.000\right)$.

\section{Table 3 about here}

Of our control variables representing individual respondent characteristics, about 40 percent are statistically significant and with the same direction of effects in both samples (Tables 2 and 3). With the exception of larger household size, other significant effects across both samples represent physical measures of individual health and experiences with health care when seriously ill. The positive effects of education and retirement wage on good health in the 1998 sample disappear in the slightly older, more rural "fresh sample," where significant positive effects for ethnicity and age are evident.

\section{Summary and Implications}

Our study is based on two goals: (1) to examine how elder health is affected by macro-level measures of regional resources and socio-environmental conditions, and (2) to test the results from our model by employing a second cross-sectional sample obtained within a two-year time period from the same population and by the same agency.

We selected the first two waves of a unique dataset, the Chinese Longitudinal Healthy Longevity Survey (CLHLS), which includes members of the oldest-old (ages $80+$ years). We employ logistic regression to estimate coefficients for elder health in 1998, the baseline year of the CLHLS, adding province-level environmental measures and province-level socio-demographic indicators. We control for measures of social, demographic, health and economic characteristics of respondents. Next, we applied the same estimation model to the replacement sample of the second wave of the CLHLS collected two years later.

The results show that the macro-measures in both our models are consistent predictors of elder self-rated health in both samples. We find that a higher percentage of a province's GDP spent on anti-pollution projects increases the likelihood of good health, as do a higher percentage of residents having access to sanitary toilets in rural areas.

A higher old-age dependency ratio has a negative effect on good health, suggesting that greater competition for resources is associated with poorer health of elderly members. We also found a negative association in both models between higher percentage of rural populations with water sanitation improvement and good health. This unexpected finding could represent evidence of poorer health (real and perceived) by rural elders as industrial-based economic development activities increase, such as drilling for well water. ${ }^{7}$ To date, however, we have not identified published studies finding negative effects on elder health from improvements in water sanitation. It also is possible that funds spent on water improvement at the province level limits availability of funds that could support elder health in more direct ways, such as regular contact with local health care providers. The negative association between water sanitation improvement and good health in rural areas clearly deserves further research attention.

Our regional quality-of-life measures have significant independent effects on elder self-reported health in addition to the more "objective" measures of individual-level physical health (e.g., physical activities, ADL measures). We interpret our results to mean that our macro-measures represent the portion that is responsible for the independent predictive power of elder self-rated health's association with mortality. We are examining this possibility in ongoing research with Chinese elders employing qualitative methods. 
Our findings in this paper properly apply to elders of the 22 sampled provinces, nearly all of whom are in the coastal area of China, and only for elders age 80 and older. (The first two waves of the CLHLS did not collect data for the younger elders, ages 65-79.) Also, it would be preferable to have macro-measures for the same two time periods our sample data were collected. (See Note 3) However, given the relatively short time periods between each sample and collection of the macro-measures ( 7 years for the 1998 data, and 5 years for the replacement sample), changes in province-level environmental conditions or demographic characteristics probably would not have major influences on elder health. (See Note 3) Hopefully, future research will be able to employ macro-measures that are causally prior in time to elder health outcomes. Finally, any coverage error associated with the CLHLS sampling strategy, as well as any influences between the collection of individual-level data and province-level data, likely have little if any impact on the second part of our analysis a validation test of our model.

Overall, the results of our study suggest that our original model is a consistent predictor of elder health, and adds support to the emerging literature that macro-measures are important in understanding elder health. Our findings emerge under controls for a variety of individual-level measures of social, demographic, economic, and health measures, including health status, physical activity levels, and several indicators of SES. Moreover, we validate our model by employing the "fresh sample" using comparable cross-sectional datasets, thus avoiding attrition occurring in longitudinal datasets of elders. We anticipate that our current research using qualitative approaches and taped interviews to examine how elders, including ethnic minorities, make judgments to answer questions about their health and age will reveal subtle and likely complicated meanings of these self-ratings, and perhaps provide new insights about the impact of macro-measures such as those we have examined in this paper.

\section{Acknowledgements}

Data used for this research were provided by the longitudinal study titled "Chinese Longitudinal Healthy Longevity Survey" (CLHLS), managed by the Center for Healthy Aging and Family Studies, Peking University. CLHLS is supported by funds from Duke University under an award from the U.S. National Institutes on Aging (NIA)(R01 AG23627-01; PI: Zeng Yi), and by China Natural Science Foundation, China Social Science Foundation, UNFPA, and Hong Kong Research Grant Council.

\section{References}

Berkman, Lisa F., Thomas Glass, Ian Brissette and Teresa E. Seeman. (2000). From social integration to health: Durkheim in the new millennium. Social Science and Medicine, 51, 843-857.

Chan, H.S., K. K. Wong, K.C. Chueng, and J.M. Lo. (1995). The implementation gap in environmental management in China: The case of Guangzhou, Zhengzhou, and Nanjing. Public Administration Review, 55 (4), 333-340.

China Ministry of Water Resources. (2010). Water Resources in the People's Republic of China. [Online] Available: http://www.mwr.gov.cn/english/sdw.html (January 17, 2010).

China Population Statistics Yearbook. (2006). Department of Population and Employment Statistics, National Bureau of Statistics of China. Beijing: China Statistics Press.

China Statistical Yearbook on Environment. (2006). National Bureau of Statistics, State Environmental Protection Administration. Beijing: China Statistics Press.

Coale, A.J., and S. Li. (1991). The effect of age misreporting in China on the calculation of mortality rates at very high ages. Demography, 28(2), 293-301.

Daly, Mary C.; Greg J. Duncan; George A. Kaplan; and John W. Lynch. (1998). Macro-to-micro links in the relation between income inequality and mortality. The Milbank Quarterly, 76(3), 315-339.

Ferraro, Kenneth F. (1980). Self-ratings of health among the old and the old-old. Journal of Health and Social Behavior, 21, 377-383.

Ferraro, Kenneth F. and Melissa M. Farmer. (1999). Utility of health data from social surveys: Is there a gold standard for measuring morbidity? American Sociological Review, 64, 303-315.

Gu, Danan. (2008). General data quality assessment of the CLHLS. In Zeng, Yi, D.L. Poston, D.A. Vlosky, and D. Gu. (eds.), Healthy Longevity in China: Demographic, Socioeconomic, and Psychological Dimensions. Springer Publishers.

[Online] http://www.geri.duke.edu/china_study/General\%20Data\%20Assessment\%20of\%20CLHLS.pdf (January 14, 2009). 
$\mathrm{Gu}$, Danan and Matthew E. Dupre. (2008). Assessment of reliability of mortality and morbidity in the 1998-2002 CLHLS waves. In Zeng, Yi, D.L. Poston, D.A. Vlosky, and D. Gu. (eds.), Healthy Longevity in China: Demographic, Socioeconomic, and Psychological Dimensions. [Online] Springer Publishers. http://www.geri.duke.edu/china_study/Mortality\%20and\%20morbidity_assessment.pdf (March 17, 2008).

He, Wan, Manisha Sengupta and Kaitai Zhang, and Ping Guo. (2007). Health and Health Care of the Older Population in Urban and Rural China: 2000. U.S. Census Bureau, International Population Reports. [Online] Washington, DC: U.S. Government Printing Office. http://www.census.gov/prod/2007pubs/p95-07-2.pdf) (November 14, 2007).

Hogan, Joseph W., Jason Roy and Christina Korkontzelou. (2004). Handling drop-out in longitudinal studies. Statistics in Medicine, 23, 1455-1497.

Holbig, Helke. (2004). The emergence of the campaign to open up the West: Ideological formation, central decision-making and the role of the provinces. China Quarterly, 178, 335-357.

Horton, Nicholas J. and Garrett M. Fitzmaurice. (2002). Maximum likelihood estimation of bivariate logistic models for incomplete responses with indicators of ignorable and non-ignorable missingness. Applied Statistics, 51(3), 281-295.

Idler, E. L., \& Benyamini, Y. (1997). Self-rated health and mortality: A review of twenty-seven community studies. Journal of Health and Social Behavior, 38, 21-37.

Jiang, Gui-Bin, Jian-Bo Shi, and Xin-Bin Feng. (2006). Mercury pollution in China: An overview of the past and current sources of the toxic metal. [Online] Environmental Science \& Technology, 40 (12) 3672-3678. DOI: 10.1021/es062707c. (January 16, 2010).

Kaneda, Toshiko. (2006). China's concern over population aging and health. Population Reference Bureau. [Online] Available: http://www.prb.org/Articles/2006/ChinasConcernOverPopulationAgingandHealth.aspx (September 16, 2009).

Kinsella, Kevin and Victoria A. Velkoff. (2001). An Aging World: 2001. U.S. Census Bureau, Series P95/01-1. Washington, DC: U.S. Government Printing Office.

Lee, Liming. (2004). The current state of public health in China. Annual Review of Public Health, 25, $327-339$.

Li, Yuhui and Linda Dorsten. (2010). Regional and urban/rural differences of public health in China. Global Journal of Health Science, 2 (1).

Liu, Yuanli, Keqin Rao, Timothy Evans, Yude Chen and William Hsiao. (2001). China: Increasing health gaps in a transitional economy. In Timothy Evans, Margaret Whitehead, Finn Diderichsen, Abbas Bhuiya and Meg Wirth (eds.) Challenging Inequalities in Health, From Ethics to Action. Oxford/New York: Oxford University Press.

Liu, Yuanli, Kegin Rao and William C. Hsiao. (2003). Medical expenditure and rural impoverishment in China. Journal of Health and Population Nutrition, 21 (3), 216-222.

Mansyur, Carol, Benjamin C. Amick, Ronald B. Harrist, and Luisa Franzini. (2008). Social capital, income inequality, and self-rated health in 45 countries. Social Science \& Medicine, 66, 43-56.

Mossey, J.M. and E. Shapiro. (1982). Self-rated health: A predictor of mortality among the elderly. American Journal of Public Health, 72, 800-808.

Priesser, John S., Andrzej T. Galecki, Kurt K. Lohman and Lynne E. Wagenknecht. (2000). Analysis of smoking trends with incomplete longitudinal binary responses. Journal of the American Statistical Association, 95 (452), 1021-1031.

2007 Report on the State of the Environment in China. (2008). Beijing: Ministry of Environmental Protection of P.R. China. [Online] http://english.sepa.gov.cn/standards_reports/soe/soe2007/200909/t20090902_159731.htm (January 17, 2010).

Robert, Stephanie A. (1998). Community-level socioeconomic status effects on adult health. Journal of Health and Social Behavior, 39, 18-37.

Robert, Stephanie A. and James S. House. (2000). Socioeconomic inequalities in health: integrating individual-, community-, and societal-level theory and research. In Gary L. Albrecht, Ray Fitzpatrick and Susan C. Scrimshaw (eds.) The Handbook of Social Studies in Health \& Medicine. London: Sage Publications Ltd. 
Ross, Catherine E. and Chloe E. Bird. (1994). Sex stratification and health lifestyle: Consequences for men's and women's perceived health. Journal of Health and Social Behavior, 35, 161-178.

Sen, Amartya. (1998). Mortality as an indicator of economic success and failure. The Economic Journal, 108(446), 1-25.

Shih, Victor. (2004). Development, The second time around: The political logic of developing western China. Journal of East Asia Studies, 4, 427-451.

Shao, Min, Xiaoyan Tang, Yuanhang Zhang, Wenjun Li. (2006). City clusters in China: Air and surface water pollution. Frontiers in Ecology and the Environment 4 (7), 353-361. doi: 10.1890/1540-9295(2006)004[0353:CCICAA]2.0.CO;2.

Subramanian, S. V., Kim, D. J., \& Kawachi, I. (2002). Social trust and self-rated health in us communities: A multilevel analysis. Journal of Urban Health, 79(4), S21-S34.

Walder, Andrew. (2003). Sociological dimensions of China's economic transition: Organization, stratification, and social mobility. [Online] Stanford, CA: Asia/Pacific Research Center, Stanford University. http://APARC.stanford.edu/publications (November 20, 2007).

Wang, Mark, Michael Webber, Brian Finlayson, and Jon Barnett. (2006). Rural industries and water pollution in China. Journal of Environmental Management, 86, 648-659.

Wilkinson, Richard G. (2002). The epidemiologic transition: From material scarcity to social disadvantage? In Frank Trovato (ed.) Population and Society, Essential Readings, Oxford, UK: Oxford University Press, 107-116.

Wilson, William. (1987). The Truly Disadvantaged: The Inner City, the Underclass, and Public Policy. Chicago, IL: University of Chicago Press.

Wong, Chit-Ming, Chun-Quan Ou, King-Pan Chan, Yuen-Kwan Chau, Thuan-Quoc Thach, Lin Yang, Roger Yat-Nork Chung, Graham Neil Thomas, Joseph Sriyal Malik Peiris, Tze-Wai Wong, Anthony Johnson Hedley, and Tai-Hing Lam. (2008). The effects of air pollution on mortality in socially deprived urban areas in Hong Kong, China. Environmental Health Perspectives, 116 (9), 1189-1194. doi:10.1289/ehp.10850 [Online] Available: $h t t p: / / d x$.doi.org/ [9 July 2008].

Zhang, Weiqing. (1999). Family Planning Program. A speech at the Population Council by the Minister in Charge of the State Family Planning, Commission of China, July 2.

Zhang, Yunhui, Wei Huang, Stephanie J. London, Guixiang Song, Guohai Chen, Lili Jiang, Naiqing Zhao, Bingheng Chen, 1 and Haidong Kan. (2006). Ozone and Daily Mortality in Shanghai, China. Environmental Health Perspectives 114 (8), 1227-1232. doi:10.1289/ehp.9014 [Online] Available: http://dx.doi.org/[18 May 2006]. http://www.unescap.org/esid/psis/population/database/poplaws/law_china/ch_record023.htm (November 24, 2007).

Zeng, Yi. (2002). Introduction to the Chinese Longitudinal Healthy Longevity Survey (CLHLS). In Zeng, Yi, D.L. Poston, D.A. Vlosky, and D. Gu. (eds.), Healthy Longevity in China: Demographic, Socioeconomic, and Psychological Dimensions. Springer Publishers. [Online] Available: http://www.springerlink.com/content/u7177376p2470566/ (September 12, 2009).

Zeng, Yi. (2004). Chinese Longitudinal Healthy Longevity Survey and some research findings. Geriatrics and Gerontology International, 4 (Supplement 1), S49-S52.

Zeng, Yi and Danan Gu (2008). Reliability of age reporting among the Chinese oldest-old in the CLHLS datasets. In Zeng, Yi, D.L. Poston, D.A. Vlosky, and D. Gu. (eds.), Healthy Longevity in China: Demographic, Socioeconomic, and Psychological Dimensions. [Online] Springer Publishers. www.geri.duke.edu/china_study/Age-reporting.pdf (December 1, 2007).

Zeng, Yi, James W. Vaupel, Xiao Zhenyu, Zhang Chunyuan, and Liu Yuzhi. (2001). The Healthy Longevity Survey and the active life expectancy of the oldest old in China. Population: An English Selection, Biodemographic Perspectives on Human Longevity, 13 (1), 95-116.

Zimmer, Zachary and Julia Kwong. (2004). Socioeconomic status and health among elder adults in rural and urban China. Journal of Aging and Health, 16(1), 44-70.

Zimmer, Zachary, Josefina Natividad, Hui-Sheng Lin, and Napaporn Chayovan. (2000). A cross-national examination of the determinants of self-assessed health. Journal of Health and Social Behavior, 41, 465-481. 


\section{Notes}

${ }^{1}$ See Zeng et al. (2001) for a discussion of the sample design and assessment of data quality for the 1998 baseline wave, and Zeng (2002) for information about the CLHLS study design and sample distribution.

${ }^{2}$ The first two waves of the CLHLS did not collect data for the younger elders, ages 65-79.

${ }^{3}$ Our province-level variables are measured in 2005. Demographic, socio-economic, and environmental data were collected on the sampled counties and cities in the CLHLS, although they were not yet available for the present study. Although we searched for similar data for the years our data were collected, to date we have not located such sources. We suspect that systematic collection of environmental data at the province level or lower by government census or private survey did not begin until sometime after the year 2000 .

${ }^{4}$ Preliminary analysis revealed that a dummy variable indicating whether respondent lived in a coastal or non-coastal province was highly correlated with several of our macro measures, namely industrial waste water meeting discharge standards, percentage of rural population with access to water sanitation improvement, percentage of GDP investment in anti-pollution projects, and life expectancy. Therefore we excluded the coastal residence variable in order to retain the more specific quality-of-life measures.

${ }^{5}$ Information for the 1998 wave about distribution of proxy subjects by age group, wave and subject, as well as characteristics of those lost to follow up in 2000, is available in $\mathrm{Gu}$ (2008).

${ }^{6}$ More than $30 \%$ of those newly recruited but not for replacement in the 2000 dataset were centenarians. When the 2000 survey was approaching its end the CLHLS found that the age distribution of the samples was distorted, and requested survey companies to re-survey centenarians (Danan Gu, 2009, personal communication).

${ }^{7}$ The possible negative effect of drilling for water wells was suggested by a reviewer of an earlier draft of our paper. Mining (gold and mercury), along with the chemical industry and coal combustion, are the more important anthropogenic pollution sources (Jiang et al. 2006, p. 3674). As far as we can identify, however, no published study has reported a relationship between well drilling for water and mining in China. 
("fresh sample")

Baseline Replacements

$(n=6,835) \quad(n=3,763)$

\section{Province-level Measures}

Percent/Mean

\section{Environmental Conditions}

$\%$ Industrial waste water meeting discharge standards

$\%$ Access rate to sanitary toilets in rural areas

$\%$ Rural population w/access to water sanitation improvement

$\%$ GDP investment in anti-pollution projects

\section{Demographic Characteristics}

$\%$ Adult population illiterate (15+ yrs).

Old age dependency ratio (\%)

Life expectancy (yrs.)

\section{Respondent Characteristics}

Self-rated health $(1=$ very good/good $)$

Age (1= above median)

Female (1=yes)

Ethnicity (1=non-Han)

Marital status $(1=$ married $)$

Occupation, age $60(1=\text { farmer })^{1}$

0.52

Any education ( $1=$ yes)

Main source of financial support is retirement wage (1=yes)

Rural residence $(1=$ yes $)$

Household size (1=above median $3+$, excludes $\mathrm{R})$

Family cares for $\mathrm{R}$ when ill (1=yes)

Medical care adequate when seriously ill (1=yes)

Health status index (0-6) ${ }^{2}$

\footnotetext{
${ }^{1}$ Farmer includes agriculture, forestry, animal husbandry, and fishery workers.

${ }^{2}$ Index of whether respondent has high blood pressure, diabetes, CVD/stroke, COPD, TB, cancer.

${ }^{3}$ ADL (activities of daily life) includes whether respondent bathes, dresses, toilets, transfers, feeds self without help.

${ }^{4}$ Index of whether everyday/almost every day respondent exercises, does housework, gardens/does fieldwork, cares for animals.

${ }^{5}$ Proxy nearly always was a family member. Proxy responses included for ethnicity, occupation, education, marital status, household size, smoking status, the two activities-index measures, social activities, whether family provides sick care, self-rating of adequacy of medical service, has retirement wage. No proxy responses were permitted for self-rated health.
} 
Table 2. Logit Coefficients for Self-Rated Good Health, Y1998, weighted $(n=6,835)$

B S.E.

\section{Province-level Measures}

\section{Environmental Conditions}

$\%$ Industrial waste water meets discharge standards

$\%$ Access rate to sanitary toilets in rural areas

$.008 * * \quad .003$

$\%$ Rural population w/access to water sanitation improvement

$\%$ GDP investment in anti-pollution projects

$.913 * * * \quad .158$

\section{Demographic Characteristics}

$\%$ Adult population illiterate (15+ yrs.)

Old age dependency ratio (\%)

Life expectancy (yrs.)

\section{Respondent Characteristics}

Age (1= above median)

$-.021 \quad .054$

Female

$-.056$

.070

Non-Han ethnicity

$-.070$

Married

$.171 *$

Farmer

Any education

$.183 * * \quad .065$

Main source of financial support is retirement wage

$-.213 * * \quad .082$

Rural residence

$-.113$

.063

Household size above median

$.152 * * \quad .054$

Family provides care when ill

$-.308 * * \quad .100$

Medical care adequate when seriously ill

$1.414 * * * \quad .146$

Participates in social activities

$.315 * * \quad .121$

Current smoker

$.094 \quad .068$

Health status index (0-6)

$-.372 * * * \quad .043$

ADL index (without assistance) (0-5)

Physical activities index (0-5)

Proxy responses index (0-16)

$\mathrm{X}^{2}=659.35, \quad \mathrm{p}<.000, \mathrm{df}=24 \quad-2 \log$ likelihood $=8726.00$

$* \mathrm{p}<.05 \quad * * \mathrm{p}<.01 \quad * * * \mathrm{p}<.001$ 
Table 3. Logit Coefficients for Self-Rated Good Health, Y2000 "Fresh Sample," weighted (n=3,763)

\section{Province-level Measures}

\section{Environmental Conditions}

$\%$ Industrial waste water meets discharge standards

$\begin{array}{cr}.035 * & .011 \\ .014 * * * & .004 \\ -.013 * * * & .004 \\ .807 * * * & .217\end{array}$

\section{Demographic Characteristics}

$\%$ Illiterate adult population (15+ yrs.)

$\begin{array}{ll}.044 * & .017 \\ -.246 * * * & .036 \\ -.022 & .033\end{array}$

Life expectancy (yrs.)

$\%$ Rural population w/access to water sanitation improvement

\section{Respondent Characteristics}

Age (1= above median)

$\begin{array}{ll}.245 * * & .075 \\ -.286 * * & .104 \\ .620 * * & .183 \\ -.294 * * & .095 \\ .127 & .088 \\ -.133 & .092 \\ -.079 & .123 \\ -.062 & .087 \\ .292 * * * & .080 \\ .213 & .122 \\ 1.770 * * * & .167 \\ .776 * * * & .180 \\ .092 & .104 \\ -.439 * * * & .061 \\ .406 * * * & .053 \\ .354 * * * & .033 \\ -.024 * * & .009 \\ -6.585 * & 2.190\end{array}$

Female (1=yes)

Ethnicity (1=non-Han)

Marital status ( $1=$ married)

Occupation, age 60 (1=farmer)

Any education $(1=$ yes $)$

Main source of financial support is retirement wage (1=yes)

Household size (1= above median)

Family provides care when ill (1=yes)

Medical care adequate when seriously ill (1=yes)

Current smoker ( $1=$ yes)

Health status index (0-6)

ADL index (without assistance) (0-5)

Physical activities index (0-5)

Proxy responses index (0-16)

Intercept

$\mathrm{X}^{2}=670.77, \quad \mathrm{p}<.000, \mathrm{df}=24 \quad-2 \log$ likelihood $=4510.15$

$* \mathrm{p}<.05 \quad * * \mathrm{p}<.01 \quad * * * \quad \mathrm{p}<.001$

"'Fresh sample" includes only elders first interviewed in 2000 to replace those lost to follow-up or death since 1998 wave, and new added elders in 2000. (See Note 6 for additional information about new added elders.) 